\title{
Modeling and Dynamic Monitoring of Ecosystem Performance in the Yukon River Basin
}

\section{Introduction}

Central Alaska is ecologically sensitive and experiencing stress in response to marked regional warming. Resource managers would benefit from an improved ability to monitor ecosystem processes in response to climate change, fire, insect damage, and management policies and to predict responses to future climate scenarios. We have developed a method for analyzing ecosystem performance as represented by the growing season integral of normalized difference vegetation index (NDVI), which is a measure of greenness that can be interpreted in terms of plant growth or photosynthetic activity (gross primary productivity). The approach illustrates the status and trends of ecosystem changes and separates the influences of climate and local site conditions from the influences of disturbances and land management.

We emphasize the ability to quantify ecosystem processes, not simply changes in land cover, across the entire period of the remote sensing archive (Wylie and others, 2008). The method builds upon remotely sensed measures of vegetation greenness for each growing season. By itself, however, a time series of greenness often reflects annual climate variations in temperature and precipitation. Our method seeks to remove the influence of climate so that changes in underlying ecological conditions are identified and quantified. We define an "expected ecosystem performance" to represent the greenness response expected in a particular year given the climate of that year. We distinguish "performance anomalies" as cases where the ecosystem response is significantly different from the expected ecosystem performance. Maps of the performance anomalies (fig. 1) and trends in the anomalies give valuable information on the ecosystems

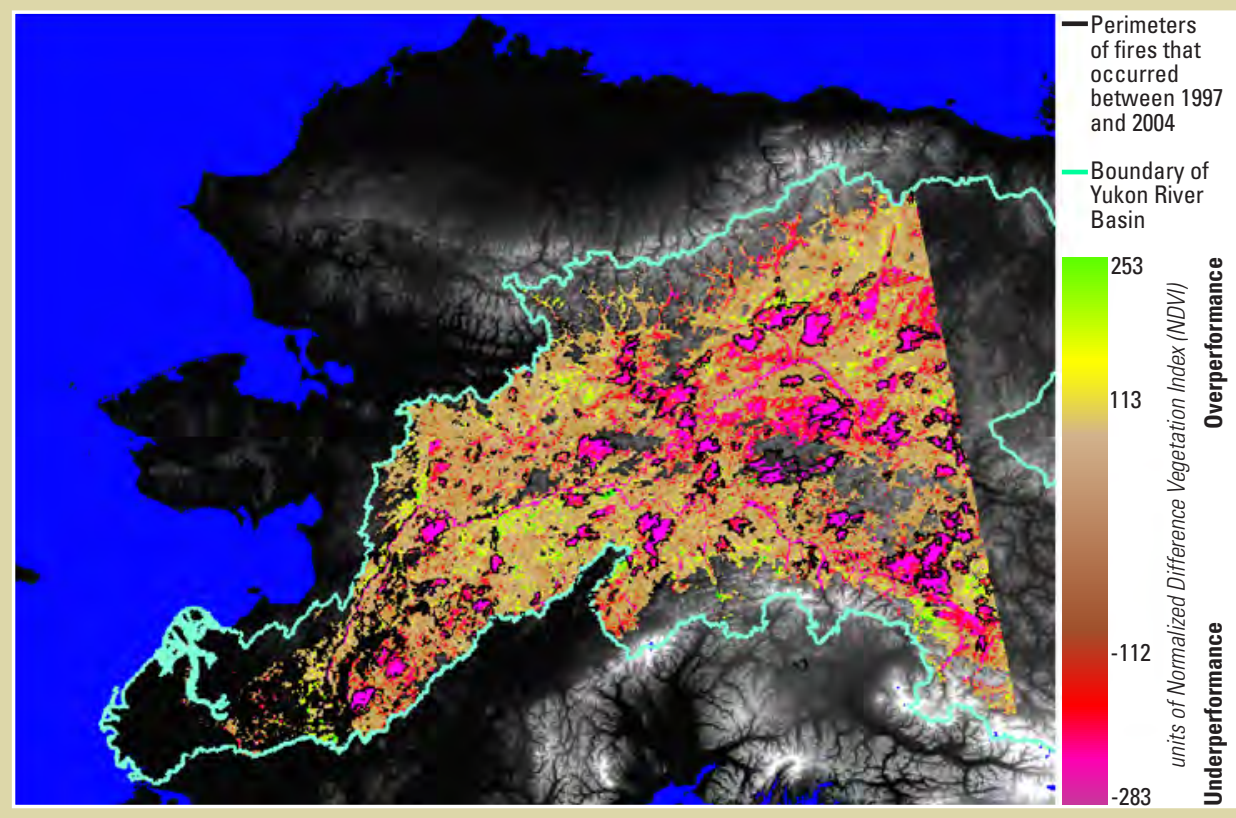

Figure 1. Ecosystem performance anomaly for 2004, with perimeters of fires that occurred between 1997 and 2004. The colored portion of the image represents the boreal forest areas of Alaska within the Yukon River Basin.

for land managers and policy makers at a resolution of $1 \mathrm{~km}$ to $250 \mathrm{~m}$.

\section{Methods}

A model is developed from random pixels representing a range of yearly climatic conditions and numerous site conditions to predict growing season NDVI (expected ecosystem performance). Yearly maps of expected growing season NDVI are constructed from this model with the use of spatial climatic data and site potential values. Site potential is the historical performance related to elevation, slope, aspect, soils, and other factors. Dry years have lower expected ecosystem performance and wet years have higher expected ecosystem performance. Areas that do not perform within the normal range determined by the regression tree model's expected error are identified as ecosystem performance anomalies. These anomalies are areas that are responding to climatic conditions differently from that of most other areas.

\section{Results}

Ecosystem performance anomaly maps were produced for each year from 1996 to 2004 . The map in figure 1 shows the 2004 season. The maps were colored to reflect negative anomalies (underperforming), positive anomalies (overperforming), and normal pixels as determined in figure 2 . Numerous underperforming anomalies were associated with burn severity in areas with confirmed forest fires. Other explanations for underperformance were insect infestations and a drier soil associated with a thickening soil active layer. Overperforming areas were mostly areas of expanding deciduous forest. The northern limits and higher elevations of the boreal forest are also experiencing more favorable growing conditions because of climate change. 


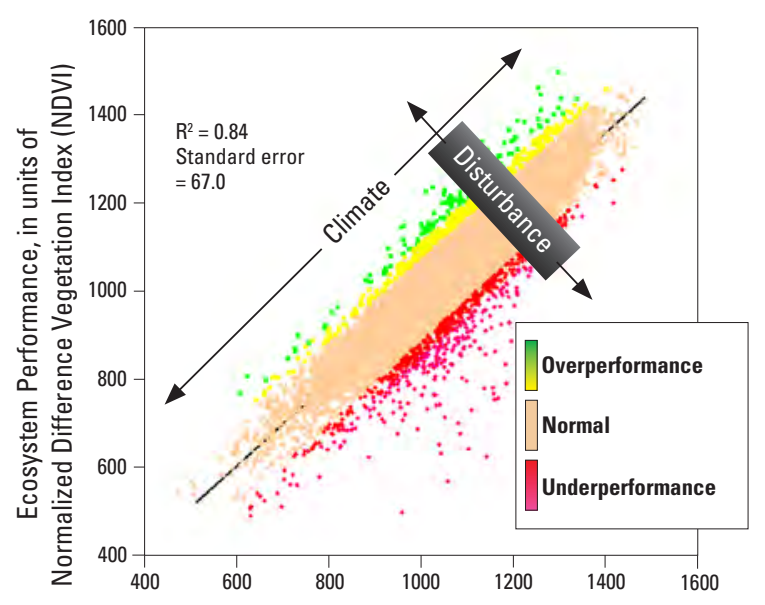

Expected Ecosystem Performance, in units of Normalized Difference Vegetation Index (NDVI)
Figure 2. Model predictions of expected ecosystem performance compared with actual ecosystem performance for multiple years. Pixels were selected randomly from boreal forest areas that have not burned in 25 years. Green and yellow areas represent overperformance and are greater than the 90 -percent confidence limit above the regression line. Magenta and red areas represent underperformance and are less than the 90 -percent confidence limit below the regression line.
Figure 3 shows how the ecosystem performance anomaly became more negative or positive from 1996 to 2004. Ninety percent of the area did not show a significant trend $(\mathrm{p} \geq 0.20)$ in ecosystem performance anomaly. There were more areas with negative trends than positive trends. Negative trends were commonly associated with areas where fires had occurred after 1998. Positive trends were commonly associated with areas that had burned prior to 1995 and may represent deciduous postfire species and ultimately coniferous forest recovery. There are numerous examples, however, of both positive and negative trend areas not associated with fires. The negative trends may represent areas of insects, disease, or changing permafrost and active layer thickness. The positive trends may indicate increasing deciduous forest composition.

\section{Using Ecosystem Performance}

Identification of localized areas of disturbance or "climate change hot spots" is essential for regional modeling of carbon fluxes and future dominant vegetation complexes. Including localized and fragmented non-fire disturbances at a regional scale would improve regional carbon flux estimates. Underperforming areas are areas that may benefit from interventions to enhance boreal forest health or recovery. Some of these underperforming areas may be associated with degrading permafrost-a process that can be verified through additional field data collection. Overperforming areas associated with an increasing deciduous forest component could provide vegetation-change models with spatial source locations to predict the future extent of deciduous forests.

The current (2008) availability of Moderate Resolution Imaging Spectroradiometer (MODIS) data (250-m resolution) promises higher resolution for future applications in both the United States and Canadian parts of the Yukon River Basin. Archived Advanced Very High Resolution Radiometer (AVHRR) data at a 1-km resolution for the period 1985-present will allow us to produce a complete, spatially rich and temporally detailed record of anomalous performances, trends, and abrupt changes. This project will be completed as a contribution to the International Polar Year.

By B.K. Wylie', L. Zhang ${ }^{2}$, L. Ji', L.L. Tieszen ${ }^{3}$, and N.B. Bliss ${ }^{1}$

${ }^{1}$ ASRC Research and Technology Solutions, contractor to the U.S. Geological Survey Earth Resources Observation and Science (EROS) Center. Work performed under contract 08HQCN0007.

${ }^{2}$ Science Applications International Corporation, contractor to the U.S. Geological Survey Earth Resources Observation and Science (EROS) Center. Work performed under contract $03 \mathrm{CRCN} 0001$.

${ }^{3}$ U.S. Geological Survey.

\section{References}

Wylie, B.K., Zhang, L., Bliss, N., Ji, L., Tieszen, L.L., and Jolly, M., 2008, Integrating modeling and remote sensing to identify ecosystem performance anomalies in the boreal forest, Yukon River Basin, Alaska: International Journal of Digital Earth, v. 2, p. 196-220.

\section{For more information, contact: \\ Larry L. Tieszen, Project Manager U.S. Geological Survey \\ Earth Resources Observation and \\ Science (EROS) Center \\ 47914 252nd Street \\ Sioux Falls, SD 57198-0001 \\ Phone: 605-594-6056 \\ Email: tieszen@usgs.gov}

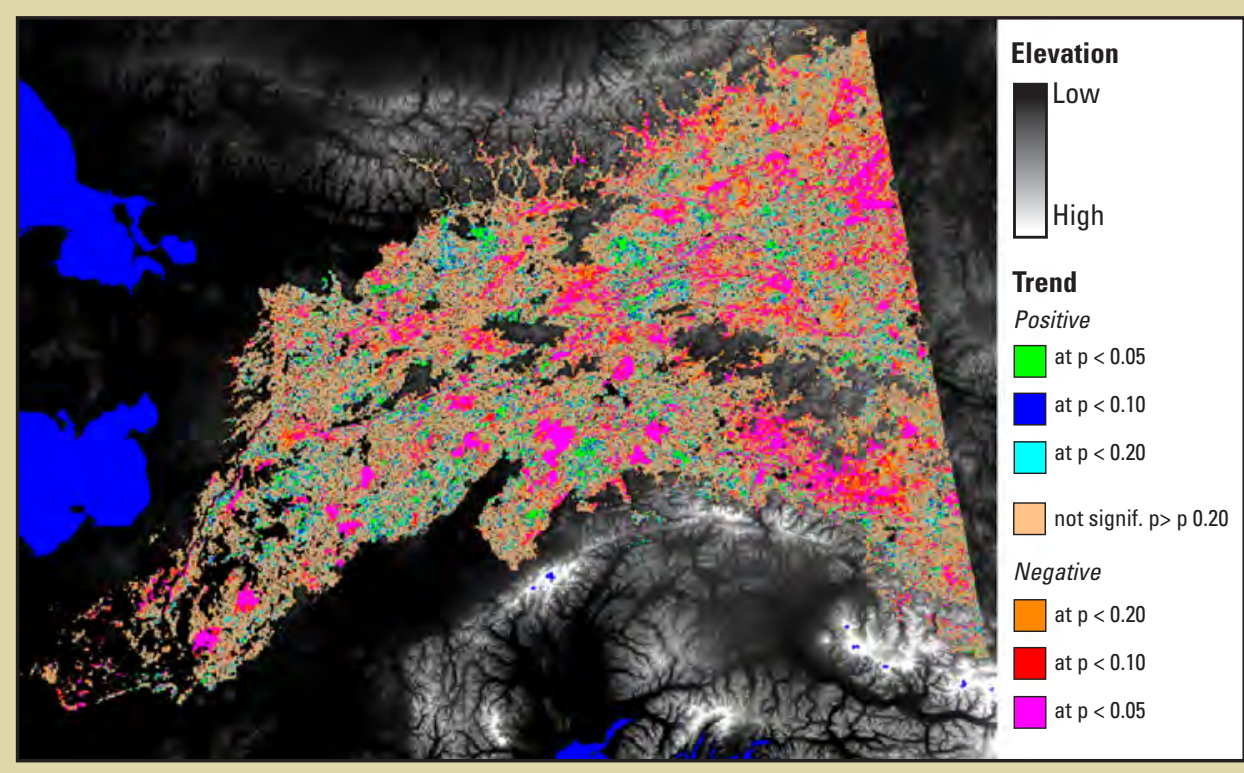

Figure 3. Ecosystem performance anomaly trends for the boreal forest region in the Yukon River Basin, Alaska, 1996-2004. The image is stratified according to the direction (positive or negative) and significance (t-test probability, p) of the slope of the regression line through the ecosystem performance anomaly values for each pixel. 